\title{
Rapid Detection of Methicillin Resistant Staphylococcus aureus Based on Surface Enhanced Raman Scattering
}

\author{
Dae Jong $\operatorname{Han}^{1,2}$ and Hyuncheol Kim${ }^{2,3}$ \\ ${ }^{1}$ Biomedical Research Institute, Seoul National University Hospital, Seoul 110-744, Korea \\ ${ }^{2}$ Interdisciplinary Program of Integrated Biotechnology, Sogang University, Seoul 121-742, Korea \\ ${ }^{3}$ Department of Chemical and Biomolecular Engineering, Sogang University, Seoul 121-742, Korea
}

\begin{abstract}
Methicillin-resistant Staphylococcus aureus (MRSA) is one of the severe nosocomial infectious agents. The traditional diagnostic methods including biochemical test, antibiotic susceptibility test and PCR amplification are time consuming and require much work. The Surface enhanced Raman spectroscopy (SERS) biosensor is a rapid and powerful tool for analyzing the chemical composition within a single living cell. To identify the biochemical and genetic characterization of clinical MRSA, all isolates from patients were performed with VITEK2 gram positive (GP) bacterial identification and Antibiotic Susceptibility Testing (AST). Virulence genes of MRSA also were identified by DNA based PCR using specific primers. All isolates, which were placed on a gold coated nanochip, were analyzed by a confocal Raman microscopy system. All isolates were identified as $S$. aureus by biochemical tests. MRSA, which exhibited antibiotic resistance, demonstrated to be positive gene expression of both femA and mecA. Furthermore, Raman shift of $S$. aureus and MRSA ( $n=20)$ was perfectly distinguished by a confocal Raman microscopy system. This novel technique explained that a SERS based confocal Raman microscopy system can selectively isolate MRSA from non-MRSA. The study recommends the SERS technique as a rapid and sensitive method to detect antibiotic resistant $S$. aureus in a single cell level.
\end{abstract}

Keywords: MRSA, SERS, Raman spectroscopy

This is an Open Access article distributed under the terms of the Creative Commons Attribution Non-Commercial License (http://creativecommons.org/licenses/by-nc/3.0) which permits unrestricted non-commercial use, distribution, and reproduction in any medium, provided the original work is properly cited.

Copyright @ 2014 The Korean Society for Clinical Laboratory Science. All rights reserved.
Corresponding author: Hyuncheol Kim Department of Chemical and Biomolecular Engineering, Sogang University, 35 Baekbeom-ro, Mapo-gu, Seoul 121-742, Korea

Tel: 82-2-705-8922

E-mail: hyuncheol@sogang.ac.kr

Received: October 16, 2014 Revised: December 28, 2014 Accepted: December 28, 2014

\section{서 론}

Staphylococcus aureus는 임상에서 흔히 분리되는 병원체로 서 화농성 감염과 패혈증 등을 유발할 수 있고(Park SY 등, 2011), 여러 가지 enterotoxin 등을 분비하기 때문에 식중독, 원내 감염 및 지역 감염 등관 관련되어 큰 문제를 일으킬 수 있다. 특히 항생제의 과잉처방으로 인하여 꾸준하게 methicillin에 대한 항생제 내성 균 주가 증가하여 methicillin resistant $S$. aureus (MRSA)는 임상에 서 일상적인 검사의 대상이 되었다(Nam HM 등, 2011).

Methicillin내성 균주는 최근 oxacillin 등을 포함한 여러 가지 항생제에 내성을 나타내는 병원체로 확대되어 그 발생빈도가 점점 증 가하고 있는 추세이며(Champion A 등, 2014) MRSA 선택배지, 항생 제 내성 검사, real time polymerase chain reaction (PCR), DNA fragment sequence analysis, pulsed-field gel electrophoresis
(PFGE) 등을 이용하여 MRSA를 분리 동정할 수 있다(Castellano $\mathrm{MJ}$ 등, 2014). 그러나 이러한 방법들은 일상적으로 사용되는 반면 오래 시간이 소요되고 여러 가지 검사 절차를 거쳐야 하기 때문에 경험과 노력이 필요하다.

전통적인 검출방법의 한계를 극복하기 위하여 nanobiotechnology 기술을 이용한 보다 정확하고 빠르게 검출할 수 있 는 기술 개발 연구가 진행되고 있다(Lu X 등, 2013). Raman spectroscopy는 다양한 세균의 형태학적 특징과 분류학적인 연구 에 많이 이용되고 있으며 세균의 세포벽의 항생제유도로 인한 화학 적 변화까지도 동정 및 구별이 가능하다(Liu TT 등, 2009). 게다가 Surface enhanced raman spectroscopy (SERS)라는 기술을 이용 하여 gold coated nanochip을 제작하여 raman scattering을 증 폭하면 수천 배 신호가 증폭되어 한 개의 세포단위에서 조차 구별 이 가능하다(Lin HY 등, 2014). 최근에는 이러한 세포 단백질의 구 
성성분을 이용한 세균의 동정이 활성화 되었으며 Matrix assisted laser desorption/ionization-time of flight (MALDI-TOF) 방식 의 임상검사 장비들이 이미 상용화되어 운영되고 있지만, 항생제내 성 균주의 구별은 아직 요원한 단계이다(McElvania와 Burbham, 2014).

항생제내성 균주의 세포 단위에서 신속하고 정확하게 구별하고 동정할 수 있는 SERS 기술이 MRSA를 포함한 항생제 내성 균주를 신속하게 검출할 수 있는 새로운 nano-biotechnology로 이용될 수 있을 것이다.

\section{재료 및 방법}

\section{MRSA 분리 및 생화학적 검사}

2013년 8월 서울 소재 대학병원 환자의 샘플에서 분리배양 동정 된 균주를 그람 염색, catalase test, coagulase test를 검사하였고 VITEK 2 compact (Biomerieux, Marcy l'Etoile, France)로 균명 을 동정한 후에 다시 항생제 감수성 검사키트로 $S$. aureus와 MRSA 균주를 각각 구분하였다.

\section{MRSA 핵산추출}

S. aureus ATCC 29213, S. aureus, MRSA 균주를 각각 Luria-Bertani (LB) broth $10 \mathrm{~mL}$ 에 접종 한 후에 $37^{\circ} \mathrm{C}$ 배양기에서 24시간 배양한 후 VERSAmax microplate reader (Molecular devices, $\mathrm{CA}, \mathrm{USA}) 600 \mathrm{~nm}$ 에서 optical density가 0.5가 되도록 조정한 후 각각 $1 \mathrm{~mL}$ 을 취하여 $14,000 \mathrm{rpm}$ 으로 원심분리하고 상 층액은 버리고 pellet을 모아 DNeasy mini kit (QIAGEN, CA, $\mathrm{USA}$ )와 QIAcube (QIAGEN, CA, USA)를 이용하여 DNA를 추출하 였다.

\section{3. 유전자증폭}

$\mathrm{MRSA}$ 에 특이적인 유전자 검출을 위하여 femA, mecA primer 를 이용하여 PCR을 진행하였다(Barski 등 1996; VandenbrouckeGrauls과 Krusters, 1996). PCR 반응액은 10X reaction buffer
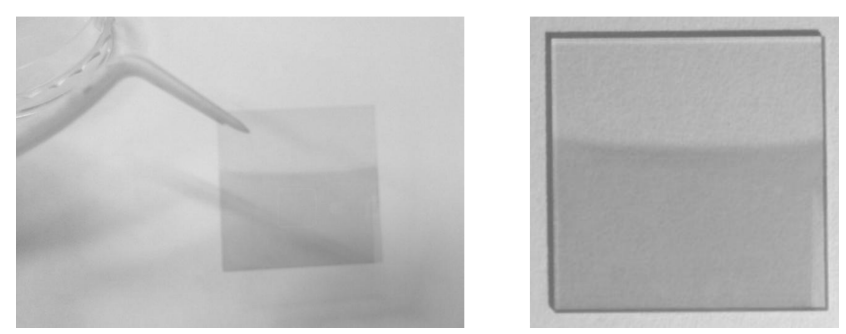

Fig. 1. Gold coated nanochip preparation.
2 uL, dNTP 2 uL, 10 pmol primer 1 uL, 1 U exTaq DNA polymerase, bacterial DNA 1 uL의 혼합액에 증류수를 최종 20 uL로 첨가하여 T3000 thermal cycler (Biometra, Gottingen, Germany)에서 증폭시켰다. PCR 산물은 $1.5 \%$ agarose gel에서 $100 \mathrm{~V}$ 로 30분간 전기영동하고 UV image analyzer (Bio-Rad, CA, $\mathrm{USA})$ 로 확인하였다.

\section{4. 나노칩 제작}

Gold particle을 전기화학적 방법을 이용하여 Indium Tin Oxide (ITO) substrate에 고정시켰다. Au nano-dot-deposited ITO substrate를 이용하여 제작된 fabricate gold nano-island film (GNIF)을 사용하기 전까지 건조시켜 보관했다(An JH 등, 2011) (Fig. 1).

\section{5. 라만 분석}

Gold coated nanochip 위에 0.1 mL 1X PBS (pH 7.4)를 이용하 여 Blood agar plate에서 자란 S. aureus ATCC 29213, S. aureus, MRSA 단일 집락을 얇게 펴서 바르고 실온에서 약 10 분 정도 건조 시켰다. 각각의 검체가 얇게 코팅된 슬라이드를 inverted optical microscope (Olympus IX71)로 먼저 관찰한 후에 $785 \mathrm{~nm}$ 의 파장 을 방출하는 레이저 광원의 NTEGRA spectroscopy (AFM-Raman Spectrometer, NT-MDT, Russia)로 분석하였다(El-Said 등, 2011).

\section{결 과}

\section{1. 생화학적 검사}

이번 연구에 이용된 S. aureus ATCC 29213, S. aureus, MRSA 등 모든 균주는 그람 양성 구균, catalase test 양성, coagulase test 양성으로 동정되었으며 VITEK 2 compact로 동정한 결과 모두 $S$. aureus로 동정되었다. MRSA를 구분하기 위하여 항생제 감수성 검

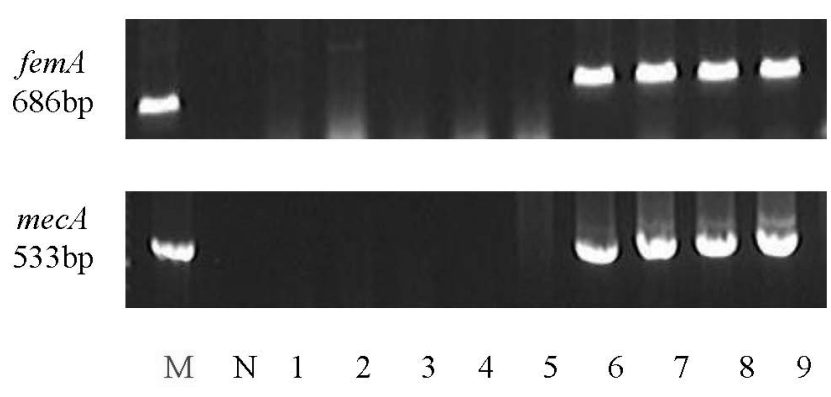

Fig. 2. Agarose gel electrophoresis of femA and mecA PCR products. M, marker; N, negative control; 1, S. aureus ATCC 29213; 2-5, S. aureus; 6-9, MRSA. 

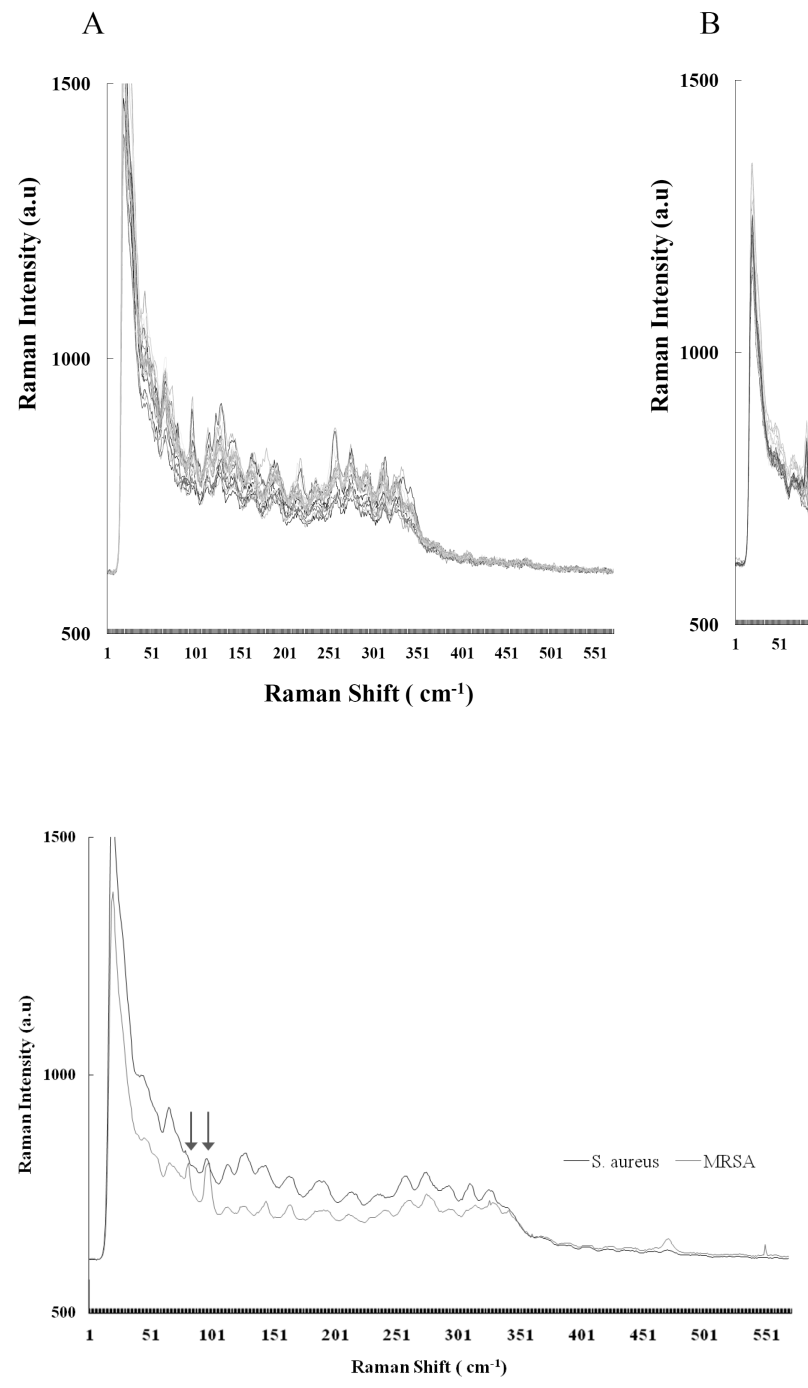

Fig. 4. Average raman shift of $S$. aureus and MRSA.

사키트로 MRSA 균주와 $S$. aureus 균주를 각각 분리 확인하였으며 MRSA 균주는 모두 Oxacillin $2 \mathrm{ug} / \mathrm{mL}$ 이상의 내성을 나타냈다.

\section{2. 특이적 유전자 증폭}

$\mathrm{MRSA}$ 의 항생제 내성과 연관된 특이적인 유전자 검출을 $\mathrm{femA}$, $m e c A$ primer를 이용하여 PCR을 진행한 결과 $\mathrm{MRSA}$ 균주들은 모 두 특이적인 밴드가 관찰되었으며, S. aureus ATCC 29213, S. aureus는 femA, mecA에서 밴드가 관찰되지 않았다(Fig. 2).

\section{SERS 기법을 이용한 MRSA의 분리동정}

Gold coated nanochip을 이용하여 S. aureus 세포벽의 단백질 구성에 대한 신호를 증폭시켜 raman signal을 측정한 결과 $S$. aureus와 MRSA의 Raman signal peak는 상당히 다르게 구분이 되었다. 특히 SERS signal peak intensity의 차이로 인하여 Raman
Fig. 3. Raman graph of $S$. aureus and MRSA. (A) S. aureus raman data, $\mathrm{n}=20$, (B) MRSA raman data, $\mathrm{n}=20$.

shift가 발생하였으며 각각 20개의 단일 세포 S. aureus와 MRSA를 신속하고 명확하게 구별하였다(Fig. 3). 또한 MRSA의 평균 raman signal peak를 구성하여 샘플을 측정하여 MRSA와 $S$. aureus의 peak pattern을 구별하여 MRSA만을 동정할 수 있었다(Fig. 4).

\section{고 찰}

$\mathrm{MRSA}$ 는 식품, 환경 등에 흔히 존재하며 원내 감염의 주요원인 으로 임상 검체에서 흔하게 분리가 된다. $\mathrm{MRSA}$ 는 점점 원내감염의 주요 원인이 되며 화농성 질환, 패혈증 등을 야기하고 이를 막기 위 해 여러 가지 노력을 하지만 발생 빈도가 점차 증가하는 추세의 병 원체이다. MRSA는 oxacillin, penicillin 등 여러 가지 항생제 내성 을 보이며 면역저하환자나 만성질환환자 등에서 더욱 발생빈도가 높고 치료가 어려우며 이러한 항생제 내성을 야기시키는 특이적인 유전자로 femA, mecA, necA, Sa442, coa, hla, hlb 등이 있으며 이러한 유전자의 확인을 통해 MRSA 감염여부를 확정할 수 있다. 최근에는 분자진단의 증가로 인하여 real time PCR로 대부분 동정 이 가능하며 이러한 결과는 생화학적 검사, 항생제 감수성 검사 등 을 기반으로 진행해야 하기 때문에 시간과 노력이 많이 소요되고 여러 가지 검사과정을 거쳐야 하기 때문에 그 절차와 비용이 많이 든다.

본 실험에서 생화학적, 표현형적 방법으로 분리된 MRSA 균주는 모두 항생제 감수성 검사에 내성을 나타내었으며 MRSA에 특이적 인 femA, mecA 유전자도 보유하고 있었다. PCR 검사방법은 항생 제 내성 유전자를 지닌 MRSA를 구별하기에는 좋은 방법이기는 하 지만 3 4일 배양에 생화학적 검사를 거쳐 진행해야 하기 때문에 시간이 오래 걸리고 또한장비와 제반 연구시설이 갖추어져야가능 
하다. 따라서 MRSA가 한 개의 세포 단위로 존재할 때 MRSA가 분 리 동정 되지 않을 수도 있기 때문에 한 개의 시료에서 분리된 여러 개의 집락을 개별적으로 빠르게 검사한다면 이러한 검사의 오류를 줄일 수 있을 것이다.

Gold coated nano-biochop을 이용한 MRSA의 신속검출은 이 러한 단점을 극복해 줄수 있는 새로운 기법이라 할 수 있을 것이다. 한 개의 세포 단위의 집락을 SERS 기법으로 세포벽 성분의 스펙트 럼을 분석하면 고유의 세포벽 성분들이 다르기 때문에 raman signal scattering 현상이 다르게 발생하고 이러한 결과로 균주에 대한 특별한 전처리 없이 S. aureus와 MRSA의 구별이 수분 내에 가 능하게 된다. 더욱이 단일세포 단위로 측정이 가능하기 때문에 여 러 개의 집락이 있어도 모두 측정이 가능하고 빠르고 정확한 결과 를 도출할 수 있게 된다.

이러한 raman spectrum은 gold를 이용한 신호의 증폭으로 가 능하기 때문에 nano-biotechnology를 접목한 항생제 내성 균주 의 동정은 진단검사 분야에서 “Lab-on-a-chip”에 가장 근접한 기 술로 제시될 수 있을 것이다.

\section{Acknowledgements: None \\ Funding: None \\ Conflict of interest: None}

\section{References}

1. An JH, El-Said WA, Yea CH, Kim TH, Choi JW. Surface-enhanced Raman scattering of dopamine on self-assembled gold nanoparticles. J Nanosci Nanotechnol. 2011, 11(5):4424-9.

2. Barski P1, Piechowicz L, Galiński J, Kur J. Rapid assay for detection of methicillin-resistant Staphylococcus aureus using multiplex PCR. Mol Cell Probes. 1996, 10(6):471-5.
3. Castellano MJ, Perozo AJ, Parra AM, Ginestre MM, Rincón GC. Antimicrobial susceptibility and polyclonal dissemination of Staphylococcus aureus strains. Rev Chilena Infectol. 2014, 31(2):165-72.

4. Champion A, Goodwin TA, Brolinson P, Werre SR, Prater M, Inzana TJ. Prevalence and characterization of methicillin-resistant. Ann Clin Microbiol Antimicrob. 2014, 13(1):33.

5. El-Said WA, Kim TH, Kim H, Choi JW. Analysis of intracellular state based on controlled 3D nanostructures mediated surface enhanced Ramanscattering. PLoS One. 2011, 6(2):e15836.

6. Lin HY, Huang CH, Hsieh WH, Liu LH, Lin YC, Chu CC, Wang ST, Kuo IT, Chau LK, Yang CY. On-line SERS Detection of Single Bacterium Using Novel SERS Nanoprobes and A Microfluidic Dielectrophoresis Device. Small. 2014, 10(22):4700-10.

7. Liu TT, Lin YH, Hung CS, Liu TJ, Chen Y, Huang YC, Tsai TH, Wang HH, Wang DW, Wang JK, Wang YL, Lin CH. A high speed detection platform based on surface-enhanced Raman scattering for monitoring antibiotic-inducedchemical changes in bacteria cell wall. PLoS One. 2009, 4(5):e5470

8. Lu X, Samuelson DR, Xu Y, Zhang H, Wang S, Rasco BA, Xu J, Konkel ME. Detecting and tracking nosocomial methicillin-resistant Staphylococcus aureus using a microfluidic SERS biosensor. Anal Chem. 2013, 85(4):2320-7.

9. McElvania TeKippe E1, Burnham CA. Evaluation of the Bruker Biotyper and VITEK MS MALDI-TOF MS systems for the identification of unusual and/or difficult-to-identify microorganisms isolated from clinical specimens. EurJ Clin Microbiol Infect Dis. 2014, 33(12):2163-71.

10. Nam HM, Lee AL, Jung SC, Kim MN, Jang GC, Wee SH, Lim SK. Antimicrobial susceptibility of Staphylococcus aureus and characterization of methicillin-resistant Staphylococcus aureus isolated from bovine mastitis in Korea. Foodborne Pathog Dis. 2011, 8(2):231-8.

11. Park SY, Son JS, Oh IH, Choi JM, Lee MS. Clinical impact of methicillin-resistant Staphylococcus aureus bacteremia based on propensity scores. Infection. 2011, 39(2):141-7.

12. Vandenbroucke-Grauls CM, Kusters JG. Specific detection of methicillin-resistant Staphylococcus species by multiplex PCR. J Clin Microbiol. 1996, 34(6):1599. 